\title{
Comparison of baricitinib, upadacitinib, and tofacitinib mediated regulation of cytokine signaling in human leukocyte subpopulations
}

lain B. McInnes ${ }^{*}$, Nicole L. Byers², Richard E. Higgs ${ }^{2}$, Jonathan Lee ${ }^{2}$, William L. Macias ${ }^{2}$, Songqing $\mathrm{Na}^{2}$, Robert A. Ortmann², Guilherme Rocha ${ }^{2}$, Terence P. Rooney ${ }^{2}$, Thomas Wehrman ${ }^{3}$, Xin Zhang ${ }^{2}$,

Steven H. Zuckerman ${ }^{2}$ and Peter C. Taylor ${ }^{4}$

\begin{abstract}
Background: The in vitro pharmacology of baricitinib, upadacitinib, and tofacitinib was evaluated to understand differences among these JAK inhibitors (JAKis) at the cellular level.

Methods: Peripheral blood mononuclear cells from healthy donors were incubated with different JAKis, levels of phosphorylated signal transducer and activator of transcription (PSTAT) were measured following cytokine stimulation, and half maximum inhibitory concentration $\left(\mathrm{I}_{50}\right)$ values were calculated in phenotypically gated leukocyte subpopulations. Therapeutic dose relevance of the in vitro analysis was assessed using calculated mean concentration-time profiles over $24 \mathrm{~h}$ obtained from JAKi-treated subjects. Time above $I \mathrm{C}_{50}$ and average daily percent inhibition of pSTAT formation were calculated for each JAKi, cytokine, and cell type.
\end{abstract}

Results: Distinct JAKis displayed different in vitro pharmacologic profiles. For example, tofacitinib and upadacitinib were the most potent inhibitors of the JAK1/3-dependent cytokines tested (interleukin [LL]-2, IL-4, IL-15, and IL-21) with lower $I_{50}$ values and increased time above $I_{50}$ translating to a greater overall inhibition of STAT signaling during the dosing interval. All JAKis tested inhibited JAK1/2-dependent cytokines (e.g., IL-6 and interferon [IFN]- $\gamma$ ), the JAK1/tyrosine kinase 2 (TYK2)-dependent cytokines IL-10 and IFN-a, the JAK2/2-dependent cytokines IL-3 and granulocyte-macrophage colony-stimulating factor (GM-CSF), and the JAK2/TYK2-dependent cytokine granulocyte colony-stimulating factor (G-CSF), but often to significantly differing degrees.

Conclusions: Different JAKis modulated distinct cytokine pathways to varying degrees, and no agent potently or continuously inhibited an individual cytokine signaling pathway throughout the dosing interval. Notably, baricitinib inhibited JAK1/3 signaling to a lesser extent than upadacitinib and tofacitinib, while upadacitinib, baricitinib, and tofacitinib inhibited the signaling of JAK2/2-dependent cytokines, including GM-CSF and IL-3, as well as the signaling of the JAK2/TYK2-dependent cytokine G-CSF.

Keywords: Baricitinib, Cytokine, Janus kinase, Phosphorylated signal transducer and activator of transcription, Potency, Receptor kinase signaling, Rheumatoid arthritis, Selectivity, Tofacitinib, Upadacitinib

\footnotetext{
*Correspondence: lain.McInnes@glasgow.ac.uk

${ }^{1}$ Institute of Infection, Immunity and Inflammation, University of Glasgow,

University Avenue, Glasgow G128QQ, UK

Full list of author information is available at the end of the article
}

(c) The Author(s). 2019 Open Access This article is distributed under the terms of the Creative Commons Attribution 4.0 International License (http://creativecommons.org/licenses/by/4.0/), which permits unrestricted use, distribution, and reproduction in any medium, provided you give appropriate credit to the original author(s) and the source, provide a link to the Creative Commons license, and indicate if changes were made. The Creative Commons Public Domain Dedication waiver (http://creativecommons.org/publicdomain/zero/1.0/) applies to the data made available in this article, unless otherwise stated. 


\section{Background}

The Janus kinase (JAK) family of cytoplasmic protein tyrosine kinases comprises JAK1, JAK2, JAK3, and tyrosine kinase 2 (TYK2). Janus kinases bind to type 1 and type 11 cytokine receptors and transmit extracellular cytokine signals to activate signal transducers and activators of transcription (STATs), which translocate to the nucleus and modulate transcription of effector genes [1]. Recent advances in the treatment of rheumatoid arthritis (RA) have been made with the use of small molecules that inhibit JAKs, specifically targeting cytokine signaling pathways implicated in RA pathogenesis [2-5].

Baricitinib and tofacitinib are JAK inhibitors (JAKis) that have been approved for the treatment of RA, and other JAKis, including upadacitinib, are in clinical development [2]. Baricitinib is approved for the treatment of moderately to severely active RA in adults in over 60 countries including European countries, Japan, and the USA. In vitro kinase assays demonstrate that baricitinib is a selective JAK1 and JAK2 inhibitor with moderate activity against TYK2 and significantly less against JAK3 [6]. Tofacitinib is a potent JAK1 and JAK3 inhibitor but is less active against JAK2 and TYK2 [7]. Upadacitinib is reported as a selective JAK1 inhibitor [8, 9]. Distinct cytokine signaling pathways are mediated by varying JAK complexes, indicating that various JAKis may have differing effects on host inflammatory responses, including those that drive RA.

Herein, we sought to study JAKis that have shown clinical efficacy in the treatment of RA and other autoimmune diseases. The objective of the study was to compare the in vitro cellular pharmacology of baricitinib, upadacitinib, and tofacitinib across relevant leukocyte subpopulations, coupled with their in vivo pharmacokinetics (PK), to determine their effects on distinct cytokine pathways, many implicated in RA pathogenesis.

\section{Methods}

\section{Leukocyte preparation and experimental design}

Whole blood samples from healthy donors $(N=4-12)$ were apheresed, and leukocyte-enriched fractions containing approximately 400 million leukocytes were transferred to the company Primity Bio (Fremont, CA, USA). Immediately following apheresis, approximately 600,000 cells were plated in $100 \mu \mathrm{L}$ into 96-well plates and incubated with JAKis using a 7-point dose range from 2 to $10,000 \mathrm{nM}$ (four-fold dilutions from the highest concentration) for $1 \mathrm{~h}$ prior to stimulation with cytokines for $15 \mathrm{~min}$ at $37^{\circ} \mathrm{C}$. Laboratory procedures ensured that compound incubation and cytokine stimulation times were kept constant across cytokines and donors, including when multiple donor samples were being processed. Baricitinib (Eli Lilly and Company), upadacitinib (synthesized by Eli Lilly), and tofacitinib citrate (ApexBio) were prepared as $10-\mathrm{mM}$ stocks in dimethyl sulfoxide. Eight cytokines were used at a concentration of $30 \mathrm{ng} / \mathrm{mL}$ (granulocyte colony-stimulating factor [G-CSF], interferon [IFN]- $\gamma$, interleukin [IL]-2, IL-4, IL-6, IL-10, IL-15, and IL-21); three others were used at different concentrations: granulocyte-macrophage colony-stimulating factor (GM-CSF) $(15 \mathrm{pg} / \mathrm{mL}), \operatorname{IFN}-\alpha(5 \mathrm{ng} / \mathrm{mL})$, and IL-3 $(2 \mathrm{ng} / \mathrm{mL})$. For the first eight cytokines, data were generated in two batches; one batch compared baricitinib to tofacitinib (6 donors) and a second batch compared baricitinib to upadacitinib (6 donors). For the remaining cytokines, data were generated in three batches; one batch compared baricitinib to upadacitinib (6 donors) and two other batches compared baricitinib to tofacitinib (2 donors/batch). The choice of cytokine concentrations and incubation conditions were optimized in order to ensure consistent signaling in alternate cell types and phosphorylated STAT (pSTAT) readouts.

\section{Flow cytometry}

After stimulation, cells were fixed, permeabilized, and fluorescence barcoded as previously described [10]. Samples were combined and stained with fluorochrome-conjugated pSTAT1 (Y701), pSTAT3 (Y705), pSTAT5 (Y694), pSTAT6 (Y641), CD3, CD4, CD20, and CD56 antibodies. Multicolor flow cytometry was used to quantify STAT phosphorylation in gated leukocyte subpopulations, and the signals from each sample were de-barcoded for statistical analysis. For a given case (stimulation, cell type, and pSTAT combination), the half maximum inhibitory concentration $\left(\mathrm{IC}_{50}\right)$ was determined if there was a consistent response to the stimulus as described in the "Statistical analysis" section. The primary pSTAT observed for each stimulus is reported. Leukocyte populations were defined as CD20+ (B cells), CD3+CD4+ (CD4+ T cells), CD3+CD4- (CD8+ T cells), CD3-CD56+ (natural killer [NK] cells), and by forward and side scatter (monocytes).

\section{Statistical analysis}

The $\mathrm{IC}_{50}$ values for JAKis were determined by analyzing the mean fluorescence intensity (MFI) of cytokine-stimulated samples in the presence of the designated concentration of compound. For a given case (stimulation, cell type, and pSTAT combination), the MFI for unstimulated and stimulated cells was determined for each donor. To ensure that a biologically relevant signal was induced, concentration-response curves (CRCs) were only analyzed when a consistent response to stimulus was observed as described below. Data were analyzed with a statistical model using an integrated data set that included a model term to account for any systematic batch effects. 


\section{Selection of cases for analysis, fitting, and selection of CRC curves}

Two sets of criteria for reporting an $\mathrm{IC}_{50}$ value were used: one at the case level and another at the individual curve level. For the CRCs to be estimated for a given case, the case had to satisfy two criteria: (c1) the minimum MFI difference between stimulated and unstimulated reads across all donors was at least 10 fluorescence units and (c2) the $p$ value of the one-sided $t$ test of the null hypothesis stimulated < unstimulated was at most 0.10 . Once a case met these two criteria, four-parameter logistic curves were fit to the 7-point curve concentration data, with the top fixed at the stimulated MFI fluorescence (ensuring all curves for the same donor had the same top parameter). Once fitted, the $\mathrm{IC}_{50}$ from a curve was accepted if the following conditions were met: (i1) the $R^{2}$ of the fitted curve was above 0.65 , (i2) the standard error (SE) of the $\log \left(\mathrm{IC}_{50}\right)$ corresponded to a fold change smaller than 8 , (i3) the SE of the slope parameter was smaller than 8 , and (i4) the difference in the MFI signal between the highest and lowest compound concentrations was larger than both half the distance between the fitted top and bottom parameters for that donor, compound curve, and the stimulated and unstimulated MFI signals for that case. If more than $25 \%$ of the curves for a compound were removed, the entire case was removed from further analysis.

\section{Estimation and comparison of mean $I C_{50}$ values}

Statistical analysis and comparison of $\mathrm{IC}_{50}$ values were conducted by fitting statistical mixed effect models to the $\log \left(\mathrm{IC}_{50}\right)$, including a random effect for donor and fixed effects for compound for each stimulation, cell type, and pSTAT combination. In cases where data were collected in multiple batches, a batch-fixed effect was added to the model to account for any systematic differences between batches. Reported $\mathrm{IC}_{50}$ values corresponded to the least squares means of the compound effects from the model. Reported $p$ values were adjusted for multiplicity by using a Bonferroni correction within each stimulant and pSTAT combination.

\section{Pharmacokinetic profiles}

The PK profiles of baricitinib were estimated from a two-compartment model with zero-order absorption that was developed using data from patients with RA from phase 2 and phase 3 clinical trials with once daily (QD) 2- or 4-mg doses [11]. The PK profiles of upadacitinib were obtained from published data using RA scaled healthy volunteer profiles in a dose-proportional manner for QD 15- or 30-mg doses [12, 13]. The PK profiles of tofacitinib were estimated from a one-compartment model with zero-order absorption using data from patients with RA from phase 3 clinical trials with twice daily 5 - or 10-mg doses [14].

\section{Estimation and comparison of time above $I C_{50}$ and daily percent inhibition}

The individual 4PL CRCs were combined with population PK curves to calculate time above $\mathrm{IC}_{50}$ and average daily percent inhibition. Protein binding effects were accounted for by replacing the in vitro $\mathrm{IC}_{50}$ with an adjusted $\mathrm{IC}_{50}$ value computed by dividing the $\mathrm{IC}_{50}$ value for each donor by the proportion of compound unbound (baricitinib 50\%, upadacitinib 54\%, and tofacitinib 60\%). The time above $\mathrm{IC}_{50}$ was defined as the time the (linearly interpolated) PK concentration was above the adjusted $\mathrm{IC}_{50}$. Protein-bound adjusted CRCs were constructed by replacing the in vitro $\mathrm{IC}_{50}$ value with the adjusted value. The average daily percent inhibition for a subject was obtained by entering the steady-state PK concentrations into the adjusted CRCs, computing the area under this curve, and dividing it by 24 $\mathrm{h}$. Using the individual donor values for time above $\mathrm{IC}_{50}$ and average daily percent inhibition, the same mixed model used to fit the $\log \left(\mathrm{IC}_{50}\right)$ values was used to estimate and compare mean times above $\mathrm{IC}_{50}$ and percent inhibitions. No transformations were undertaken to keep the estimates within the $0-24$-h range (for time above $\mathrm{IC}_{50}$ ) and $0-100 \%$ (for average daily inhibition). The values were truncated in a few cases where the estimates fell outside the range.

\section{Results}

$\mathrm{IC}_{50}$ values for JAKis in cytokine-stimulated human PBMC preparations

We first determined the specificity and potency of different JAKis in inhibiting cytokine-induced pSTATs in human peripheral blood mononuclear cells (PBMCs). Following cytokine stimulation, quantification of the inhibition of pSTATs elucidated that $\mathrm{IC}_{50}$ values for any given JAKi were similar across cell types and were dose-dependent. However, differences in $\mathrm{IC}_{50}$ values were observed between the JAKis assessed. For the JAK1/3-dependent cytokines IL-2, IL-4, IL-15, and IL-21, $\mathrm{IC}_{50}$ values were lowest (most potent) for upadacitinib and tofacitinib and highest (least potent) for baricitinib (Table 1 and Additional file 1: Table S1).

Signal inhibition was assessed in monocytes for the JAK2/2-dependent cytokines IL-3 and GM-CSF and the JAK2/TYK2-dependent cytokine G-CSF (Table 1). IC I0 $_{50}$ values for IL-3, GM-CSF, and G-CSF signal inhibition indicated highest potency for upadacitinib and baricitinib and reduced potency for tofacitinib (Table 1). A similar pattern was observed for IL-3 signal inhibition in B cells (Additional file 1: Table S1).

$\mathrm{IC}_{50}$ values for IL-6 (JAK1/2) signaling in CD4+ T cells and monocytes, and for IL-10- (JAK1/TYK2) stimulated T cells and NK cells, were similar for baricitinib, upadacitinib, and tofacitinib (Table 1 and Additional file 1: Table S1). $\mathrm{IC}_{50}$ values for pSTAT3 inhibition in IL-10- 
Table $1 \mathrm{IC}_{50}$ values in CD4+ T cells, NK cells, and monocytes

\begin{tabular}{|c|c|c|c|c|c|c|c|c|c|}
\hline \multirow[t]{2}{*}{ Stimulation/pSTAT } & \multicolumn{3}{|c|}{ CD4+ T cells } & \multicolumn{3}{|l|}{ NK cells } & \multicolumn{3}{|c|}{ Monocytes } \\
\hline & Bari (nM) & Upa (nM) & Tofa $(n M)$ & Bari (nM) & Upa (nM) & Tofa $(\mathrm{nM})$ & Bari (nM) & Upa (nM) & Tofa $(\mathrm{nM}$ \\
\hline \multicolumn{10}{|c|}{ JAK1/3-dependent cytokines } \\
\hline IL-2/pSTAT5 & 29 & $10^{* *}$ & $11^{* * *}$ & 44 & $27^{*}$ & $15^{* * *}$ & NS & & \\
\hline IL-4/pSTAT6 & 48 & $18^{* * *}$ & $18^{* * *}$ & 22 & $8^{*}$ & $8^{* * *}$ & 45 & $22^{* *}$ & $35^{*}$ \\
\hline IL-15/pSTAT5 & 40 & $17^{* * *}$ & $15^{* * *}$ & 67 & $40^{*}$ & $22^{* * *}$ & NS & & \\
\hline IL-21/pSTAT3 & 64 & $20^{* * *}$ & $22^{* * *}$ & 62 & $24^{* *}$ & $21^{* * *}$ & 85 & 34 & 37 \\
\hline \multicolumn{10}{|c|}{ JAK2/2- or JAK2/TYK2-dependent cytokines } \\
\hline IL-3/pSTAT5 & NS & & & NS & & & 26 & $12^{*}$ & $102^{* * *}$ \\
\hline G-CSF/pSTAT3 & NS & & & NS & & & 65 & 84 & $97^{* *}$ \\
\hline GM-CSF/pSTAT5 & NS & & & NS & & & 30 & $13^{* * *}$ & $97^{* * *}$ \\
\hline \multicolumn{10}{|c|}{ JAK1/JAK2/TYK2-dependent cytokines } \\
\hline IL-6/pSTAT3 & 61 & 58 & 56 & NS & & & 48 & 43 & 40 \\
\hline IL-10/pSTAT3 & 68 & 87 & 55 & 87 & 124 & 74 & 142 & $80^{* * *}$ & $104^{*}$ \\
\hline IFN- $\gamma /$ pSTAT1 & NS & & & NS & & & 38 & 30 & $46^{* * *}$ \\
\hline IFN-a/pSTAT1 & 64 & 40 & $132^{* * *}$ & 76 & 69 & $121^{* * *}$ & 97 & $44^{* *}$ & $163^{* * *}$ \\
\hline IFN-a/pSTAT3 & 27 & 17 & $51^{* * *}$ & NS & & & 14 & $6^{*}$ & $23^{* * *}$ \\
\hline IFN-a/pSTAT5 & 23 & 14 & $36^{* *}$ & NS & & & 13 & $5^{* *}$ & $22^{* * *}$ \\
\hline
\end{tabular}

Reported IC $\mathrm{C}_{50}$ values are least squares estimates of mixed models as described in the "Statistical analysis" section. For G-CSF, IFN- $\gamma$, IL-2, IL-4, IL-6, IL-10, IL-15, and IL-21, reported IC 50 values are based on two batches of data amounting to 12 donors for baricitinib and 6 donors for upadacitinib and tofacitinib; for GM-CSF, IFN$\mathrm{a}$, and IL-3, reported IC $\mathrm{S}_{50}$ values are based on three batches of data amounting to 10 donors for baricitinib, 6 donors for upadacitinib, and 4 donors for tofacitinib. The primary PSTAT observed for each stimulus is reported in the table. Protein binding was not accounted for in the $\mathrm{IC}_{50}$ calculations ${ }^{*} p<0.01,{ }^{* *} p<0.001,{ }^{* * *} p<0.0001$ compared to baricitinib

Bari baricitinib, G-CSF granulocyte colony-stimulating factor, GM-CSF granulocyte-macrophage colony-stimulating factor, $I C_{50}$ half maximum inhibitory concentration, IFN interferon, IL interleukin, JAK Janus kinase, NK natural killer, NS no stimulation, pSTAT phosphorylated signal transducer and activator of transcription, Tofa tofacitinib, TYK tyrosine kinase, Upa upadacitinib

stimulated monocytes indicated greatest potency for upadacitinib and tofacitinib and reduced potency for baricitinib (Table 1). IC 50 values for pSTAT1 inhibition in IFN- $\gamma^{-}(\mathrm{JAK} 1 / 2)$ stimulated monocytes indicated highest potency for baricitinib and upadacitinib and reduced potency for tofacitinib (Table 1 ). $\mathrm{IC}_{50}$ values for pSTAT1 inhibition in IFN- $\gamma$-stimulated B cells were similar for baricitinib, upadacitinib, and tofacitinib (Additional file 1: Table S1). Across cell types that had a response, $\mathrm{IC}_{50}$ values for IFN- $\alpha$ - (JAK1/TYK2) induced pSTAT1, 3, and 5 indicated the highest potency for upadacitinib and baricitinib and lower potency for tofacitinib (Table 1 and Additional file 1: Table S1).

\section{Time above $\mathrm{IC}_{50}$}

The potential clinical relevance of the foregoing was next evaluated by examining the likely cell subset-specific inhibition pattern in patients over a 24 -h period, according to the reported exposure levels (plasma concentrations during the daily dosing cycle) for each agent. This analysis captures "time-adjusted" inhibitory activity in terms of immune modulatory function and could differ significantly among agents with distinct PK properties. The number of hours per day JAKi concentrations were above $\mathrm{IC}_{50}$ values for each cytokine/pSTAT combination was determined using calculated $\mathrm{IC}_{50}$ values and exposure data from JAKi-treated subjects. For the JAK1/3-dependent cytokines IL-2, IL-4, IL-15, and IL-21, tofacitinib spent the most time per day above $\mathrm{IC}_{50}$ for the pSTAT induced by each cytokine across cell types tested; time above $\mathrm{IC}_{50}$ was generally sequentially less for upadacitinib and baricitinib (Table 2 and Additional file 1: Tables S2-S4, and Fig. 1a). To illustrate this pattern in NK cells, for IL-15/pSTAT5, time above $\mathrm{IC}_{50}$ was 17 and $23 \mathrm{~h}$ for tofacitinib 5- and 10-mg doses, 3.4 and 8.1 h for upadacitinib 15- and 30-mg doses, and 0 and $1 \mathrm{~h}$ for baricitinib 2- and 4-mg doses, respectively. A similar relationship was observed for IL-21/pSTAT3 (Table 2 and Additional file 1: Tables S2-S4, and Fig. 1a).

For IL-3 and GM-CSF (JAK2/2), time above $\mathrm{IC}_{50}$ for pSTAT5 inhibition in monocytes was generally highest for upadacitinib and lower for baricitinib and tofacitinib (Table 2 and Additional file 1: Table S3, and Fig. 1b, c). To illustrate this pattern, for GM-CSF/pSTAT5 in monocytes, time above $\mathrm{IC}_{50}$ was 12.6 and $18.1 \mathrm{~h}$ for upadacitinib 15- and 30-mg doses, 2.5 and $9.2 \mathrm{~h}$ for baricitinib 2- and 4-mg doses, and 2.2 and $9.0 \mathrm{~h}$ for tofacitinib 5- and 10-mg doses, respectively (Table 2 and Additional file 1: Table S3, and Fig. 1c). For G-CSF (JAK2/TYK2) in monocytes, time spent above $\mathrm{IC}_{50}$ for pSTAT3 inhibition was most for tofacitinib and 
Table 2 Hours per day above $I_{50}$ in CD4+ T cells, NK cells, and monocytes: baricitinib 4 mg

\begin{tabular}{|c|c|c|c|c|c|c|c|c|c|}
\hline \multirow[t]{2}{*}{ Stimulation/pSTAT } & \multicolumn{3}{|c|}{ CD4+ T cells } & \multicolumn{3}{|c|}{ NK cells } & \multicolumn{3}{|c|}{ Monocytes } \\
\hline & $\begin{array}{l}\text { Bari } \\
4 \mathrm{mg}\end{array}$ & $\begin{array}{l}\text { Upa } \\
15 \mathrm{mg} \\
30 \mathrm{mg} \\
\end{array}$ & $\begin{array}{l}\text { Tofa } \\
5 \mathrm{mg} \\
10 \mathrm{mg} \\
\end{array}$ & $\begin{array}{l}\text { Bari } \\
4 \mathrm{mg}\end{array}$ & $\begin{array}{l}\text { Upa } \\
15 \mathrm{mg} \\
30 \mathrm{mg} \\
\end{array}$ & $\begin{array}{l}\text { Tofa } \\
5 \mathrm{mg} \\
10 \mathrm{mg} \\
\end{array}$ & $\begin{array}{l}\text { Bari } \\
4 \mathrm{mg}\end{array}$ & $\begin{array}{l}\text { Upa } \\
15 \mathrm{mg} \\
30 \mathrm{mg}\end{array}$ & $\begin{array}{l}\text { Tofa } \\
5 \mathrm{mg} \\
10 \mathrm{mg} \\
\end{array}$ \\
\hline \multicolumn{10}{|c|}{ JAK1/3-dependent cytokines } \\
\hline IL-2/pSTAT5 & 9 & $\begin{array}{l}15.3^{*} \\
20.6^{* *}\end{array}$ & $\begin{array}{l}23.8^{* * *} \\
24.2^{* * *}\end{array}$ & 4.5 & $\begin{array}{l}6.6 \\
10.5^{* *}\end{array}$ & $\begin{array}{l}21.4^{* * * *} \\
24.0^{* * *}\end{array}$ & NS & & \\
\hline IL-4/pSTAT6 & 3.7 & $\begin{array}{l}9.9 \\
14.4^{* *}\end{array}$ & $\begin{array}{l}19.6^{* * * *} \\
24.2^{* * *}\end{array}$ & 12.6 & $\begin{array}{l}17.5 \\
22.3^{*}\end{array}$ & $\begin{array}{l}24.0^{* * * *} \\
24.0^{* * *}\end{array}$ & 4.5 & $\begin{array}{l}8.2 \\
12.3^{* *}\end{array}$ & $\begin{array}{l}12.3^{* * *} \\
19.7^{* * *}\end{array}$ \\
\hline IL-15/pSTAT5 & 5.5 & $\begin{array}{l}10.4^{* *} \\
14.5^{* * *}\end{array}$ & $\begin{array}{l}21.2^{* * *} \\
24.0^{* * *}\end{array}$ & 1 & $\begin{array}{l}3.4 \\
8.1^{* *}\end{array}$ & $\begin{array}{l}17.0^{* * *} \\
23.0^{* * *}\end{array}$ & NS & & \\
\hline IL-21/pSTAT3 & 0.7 & $\begin{array}{l}9.0^{* * *} \\
13.1^{* * *}\end{array}$ & $\begin{array}{l}17.0^{* * *} \\
23.6^{* * *}\end{array}$ & 1.2 & $\begin{array}{l}7.7^{* *} \\
11.6^{* * *}\end{array}$ & $\begin{array}{l}17.5^{* * * *} \\
23.9^{* * *}\end{array}$ & 0 & $\begin{array}{l}4.4 \\
8.6^{*}\end{array}$ & $\begin{array}{l}12.5^{*} \\
18.9^{* *}\end{array}$ \\
\hline \multicolumn{10}{|c|}{ JAK2/2- or JAK2/TYK2-dependent cytokines } \\
\hline IL-3/pSTAT5 & NS & & & NS & & & 10.1 & $\begin{array}{l}13.0 \\
18.3^{* *}\end{array}$ & $\begin{array}{l}0.3^{* * *} \\
8.1\end{array}$ \\
\hline G-CSF/pSTAT3 & NS & & & NS & & & 1.4 & $\begin{array}{l}0.1 \\
3.2\end{array}$ & $\begin{array}{l}2.3 \\
8.5^{*}\end{array}$ \\
\hline GM-CSF/pSTAT5 & NS & & & NS & & & 9.2 & $\begin{array}{l}12.6 \\
18.1^{* *}\end{array}$ & $\begin{array}{l}2.2^{* * *} \\
9.0\end{array}$ \\
\hline \multicolumn{10}{|c|}{ JAK1/JAK2/TYK2-dependent cytokines } \\
\hline IL-6/pSTAT3 & 1.9 & $\begin{array}{l}0.6 \\
5.5\end{array}$ & $\begin{array}{l}7.3^{*} \\
14.8^{* * *}\end{array}$ & NS & & & 3.6 & $\begin{array}{l}3.1 \\
7.6^{*}\end{array}$ & $\begin{array}{l}10.8^{*} \\
18.2^{* * *}\end{array}$ \\
\hline IL-10/pSTAT3 & 1.2 & $\begin{array}{l}0 \\
2.8\end{array}$ & $\begin{array}{l}7.6^{*} \\
15.1^{* * *}\end{array}$ & 0.4 & $\begin{array}{l}0 \\
0.5\end{array}$ & $\begin{array}{l}4.2^{*} \\
11.8^{* * *}\end{array}$ & 0 & $\begin{array}{l}0.6 \\
3.5\end{array}$ & $\begin{array}{l}0.8 \\
7.8^{* * *}\end{array}$ \\
\hline IFN- $-/$ pSTAT1 & NS & & & NS & & & 6 & $\begin{array}{l}5.8 \\
9.7^{*}\end{array}$ & $\begin{array}{l}9.4^{* *} \\
16.8^{* * *}\end{array}$ \\
\hline IFN-a/pSTAT1 & 0.9 & $\begin{array}{l}3.6 \\
8.1^{* *}\end{array}$ & $\begin{array}{l}0 \\
5.2\end{array}$ & 0.2 & $\begin{array}{l}0 \\
4.8^{* *}\end{array}$ & $\begin{array}{l}0.1 \\
5.7^{* * * *}\end{array}$ & 0 & $\begin{array}{l}2.9 \\
7.5^{* * *}\end{array}$ & $\begin{array}{l}0 \\
2.8^{* * * *}\end{array}$ \\
\hline IFN-a/pSTAT3 & 9.6 & $\begin{array}{l}10.4 \\
15.0\end{array}$ & $\begin{array}{l}8.0 \\
15.5^{* * *}\end{array}$ & NS & & & 18.2 & $\begin{array}{l}21.7 \\
23.7\end{array}$ & $\begin{array}{l}16.6 \\
23.2^{*}\end{array}$ \\
\hline IFN-a/pSTAT5 & 12 & $\begin{array}{l}12.9 \\
17.2\end{array}$ & $\begin{array}{l}12.2 \\
19.6^{* * *}\end{array}$ & NS & & & 19.8 & $\begin{array}{l}21.9 \\
23.5\end{array}$ & $\begin{array}{l}17.2^{*} \\
23.9^{* *}\end{array}$ \\
\hline
\end{tabular}

Reported hours per day above $\mathrm{IC}_{50}$ are least squares estimates of mixed models as described in the "Statistical analysis" section. Protein binding was accounted for in the calculations. JAKis were administered once daily (baricitinib and upadacitinib) or twice daily (tofacitinib)

${ }^{*} p<0.01,{ }^{* *} p<0.001,{ }^{* * *} p<0.0001$ compared to baricitinib $4 \mathrm{mg}$

Bari baricitinib, G-CSF granulocyte colony-stimulating factor, GM-CSF granulocyte-macrophage colony-stimulating factor, $I C_{50}$ half maximum inhibitory concentration, IFN interferon, IL interleukin, JAK Janus kinase, JAKi JAK inhibitor, NK natural killer, NS no stimulation, pSTAT phosphorylated signal transducer and activator of transcription, Tofa tofacitinib, TYK tyrosine kinase, Upa upadacitinib

upadacitinib and least for baricitinib (Table 2 and Additional file 1: Table S3).

For IL-6-induced CD4+ T cells and monocytes, time above $\mathrm{IC}_{50}$ for pSTAT3 inhibition was generally highest for tofacitinib, decreased for upadacitinib, and least for baricitinib (Table 2 and Additional file 1: Table S3, and Fig. 1d). To illustrate this pattern, for IL-6/ pSTAT3 in CD4+ T cells, time above $\mathrm{IC}_{50}$ was 7.3 and $14.8 \mathrm{~h}$ for tofacitinib 5 - and $10-\mathrm{mg}$ doses, 0.6 and $5.5 \mathrm{~h}$ for upadacitinib 15- and 30-mg doses, and 0 and $1.9 \mathrm{~h}$ for baricitinib 2- and 4-mg doses, respectively (Table 2 and Additional file 1: Table S3, and Fig. 1d). This pattern was also generally observed for JAKis in IFN- $\gamma$ induced cell types (Table 2 and Additional file 1: Tables S2-S4, and Fig. 1e). For cell types stimulated by
IL-10, time above $\mathrm{IC}_{50}$ for pSTAT3 inhibition was generally highest for tofacitinib and least for upadacitinib and baricitinib (Table 2 and Additional file 1: Tables S2-S4). For cell types stimulated by IFN- $\alpha$, time above $\mathrm{IC}_{50}$ for pSTAT inhibition was generally the most for upadacitinib and tofacitinib and the least for baricitinib (Table 2 and Additional file 1: Table S2-S4).

\section{Percent STAT inhibition}

The JAK inhibitors were next compared by calculating the percent inhibition of STAT phosphorylation over a 24-h interval to determine the functional consequence of JAK inhibition reflected by the magnitude and duration of inhibition of the phosphorylation of their most proximal substrates. Concentration-response curves combined with 

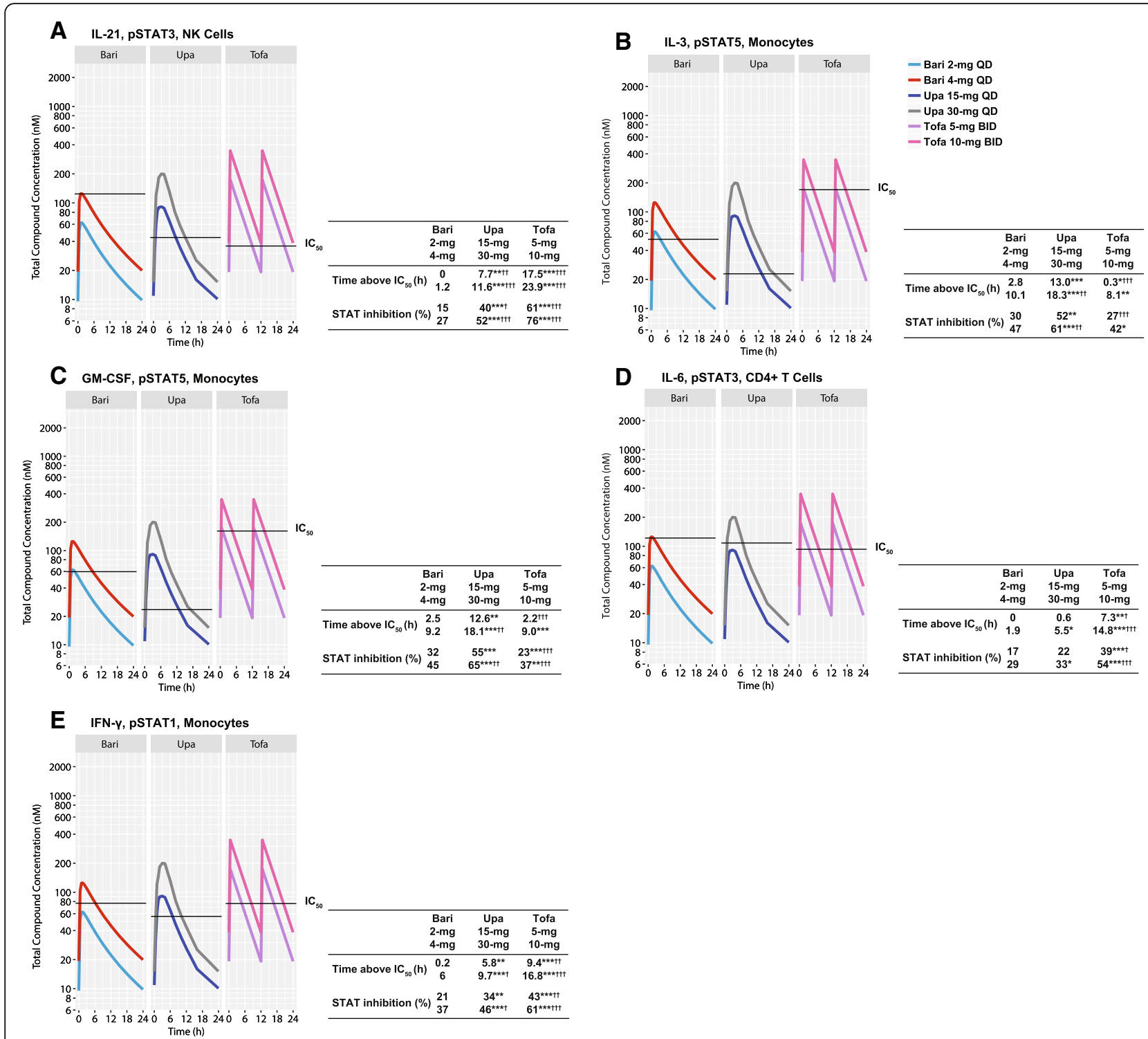

Fig. 1 JAKi exposure curves for select cytokines. The number of hours per day JAKi concentrations are above IC 50 values is shown for IL-21/ pSTAT3 in NK cells (a), IL-3/pSTAT5 in monocytes (b), GM-CSF/pSTAT5 in monocytes (c), IL-6/pSTAT3 in CD4+ T cells (d), and IFN- $/ /$ pSTAT1 in monocytes (e). Panels a-e include the average daily percent STAT inhibition. Protein binding was accounted for in the calculation of hours per day above $I_{50}$ and average daily percent STAT inhibition, and the $I_{50}$ values were corrected for the compound-bound proportion. ${ }^{*} p<0.01$, ${ }^{* *} p<0.001,{ }^{* * *} p<0.0001$ compared to baricitinib $2 \mathrm{mg} ;{ }^{t} p<0.01,{ }^{+\dagger} p<0.001,{ }^{++\dagger} p<0.0001$ compared to baricitinib 4 mg. Bari, baricitinib; BID, twice daily; GM-CSF, granulocyte-macrophage colony-stimulating factor; h, hours; IC $C_{50}$, half maximum inhibitory concentration; IFN, interferon; IL, interleukin; JAK, Janus kinase; JAKi, JAK inhibitor; NK, natural killer; PSTAT, phosphorylated STAT; QD, once daily; STAT, signal transducer and activator of transcription; Tofa, tofacitinib; Upa, upadacitinib

exposure data for JAKi-treated subjects revealed cytokinedependent similarities and differences in the magnitude of pSTAT inhibition (Table 3 and Additional file 1: Tables S5-S7). Percent STAT inhibition for IL-2, IL-4, IL-15, and IL-21 signaling (JAK1/3) was generally highest for tofacitinib and upadacitinib and least for baricitinib (Table 3 and Additional file 1: Tables S5-S7, and Fig. 1a). For example, in NK cells, percent STAT inhibition for IL-15/pSTAT5 was $62 \%$ and $79 \%$ for tofacitinib 5- and 10-mg doses, $27 \%$ and $39 \%$ for upadacitinib 15 - and 30-mg doses, and $12 \%$ and $24 \%$ for baricitinib 2- and 4-mg doses, respectively. A similar relationship was observed for IL-21/pSTAT3 (Table 3 and Additional file 1: Table S6, and Fig. 1a).

Percent STAT inhibition for IL-3 and GM-CSF (JAK2/ 2) in monocytes was generally highest for upadacitinib and sequentially less so for baricitinib and tofacitinib (Table 3 and Additional file 1: Table S6, and Fig. 1b, c). Percent STAT inhibition for GM-CSF/pSTAT5 in 
Table 3 Average daily percent STAT inhibition in CD4+ T cells, NK cells, and monocytes: baricitinib $4 \mathrm{mg}$

\begin{tabular}{|c|c|c|c|c|c|c|c|c|c|}
\hline \multirow[t]{2}{*}{ Stimulation/pSTAT } & \multicolumn{3}{|c|}{ CD4+ T cells } & \multicolumn{3}{|c|}{ NK cells } & \multicolumn{3}{|c|}{ Monocytes } \\
\hline & $\begin{array}{l}\text { Bari } \\
4 \mathrm{mg}\end{array}$ & $\begin{array}{l}\text { Upa } \\
15 \mathrm{mg} \\
30 \mathrm{mg}\end{array}$ & $\begin{array}{l}\text { Tofa } \\
5 \mathrm{mg} \\
10 \mathrm{mg} \\
\end{array}$ & $\begin{array}{l}\text { Bari } \\
4 \mathrm{mg}\end{array}$ & $\begin{array}{l}\text { Upa } \\
15 \mathrm{mg} \\
30 \mathrm{mg}\end{array}$ & $\begin{array}{l}\text { Tofa } \\
5 \mathrm{mg} \\
10 \mathrm{mg} \\
\end{array}$ & $\begin{array}{l}\text { Bari } \\
4 \mathrm{mg}\end{array}$ & $\begin{array}{l}\text { Upa } \\
15 \mathrm{mg} \\
30 \mathrm{mg}\end{array}$ & $\begin{array}{l}\text { Tofa } \\
5 \mathrm{mg} \\
10 \mathrm{mg} \\
\end{array}$ \\
\hline \multicolumn{10}{|c|}{ JAK1/3-dependent cytokines } \\
\hline IL-2/pSTAT5 & 44 & $\begin{array}{l}60^{*} \\
71^{* * *}\end{array}$ & $\begin{array}{l}78^{* * *} \\
89^{* * *}\end{array}$ & 34 & $\begin{array}{l}36 \\
48^{* *}\end{array}$ & $\begin{array}{l}72^{* * *} \\
85^{* * *}\end{array}$ & NS & & \\
\hline IL-4/pSTAT6 & 30 & $\begin{array}{l}45^{*} \\
57^{* * *}\end{array}$ & $\begin{array}{l}69^{* * *} \\
84^{* * *}\end{array}$ & 52 & $\begin{array}{l}61 \\
71^{* *}\end{array}$ & $\begin{array}{l}82^{* * *} \\
91^{* * *}\end{array}$ & 33 & $\begin{array}{l}40 \\
52^{* *}\end{array}$ & $\begin{array}{l}51^{* * *} \\
70^{* * *}\end{array}$ \\
\hline IL-15/pSTAT5 & 36 & $\begin{array}{l}47^{* *} \\
59^{* * *}\end{array}$ & $\begin{array}{l}72^{* * *} \\
85^{* * *}\end{array}$ & 24 & $\begin{array}{l}27 \\
39^{* *}\end{array}$ & $\begin{array}{l}62^{* * *} \\
79^{* * *}\end{array}$ & NS & & \\
\hline IL-21/pSTAT3 & 27 & $\begin{array}{l}44^{* * *} \\
55^{* * *}\end{array}$ & $\begin{array}{l}61^{* * *} \\
76^{* * *}\end{array}$ & 27 & $\begin{array}{l}40^{*} \\
52^{* * *}\end{array}$ & $\begin{array}{l}61^{* * *} \\
76^{* * *}\end{array}$ & 22 & $\begin{array}{l}34 \\
45^{*}\end{array}$ & $\begin{array}{l}46^{*} \\
63^{* *}\end{array}$ \\
\hline \multicolumn{10}{|c|}{ JAK2/2- or JAK2/TYK2-dependent cytokines } \\
\hline IL-3/pSTAT5 & NS & & & NS & & & 47 & $\begin{array}{l}52 \\
61^{* *}\end{array}$ & $\begin{array}{l}27^{* * * *} \\
42\end{array}$ \\
\hline G-CSF/pSTAT3 & NS & & & NS & & & 25 & $\begin{array}{l}17^{*} \\
26\end{array}$ & $\begin{array}{l}27 \\
40^{* *}\end{array}$ \\
\hline GM-CSF/pSTAT5 & NS & & & NS & & & 45 & $\begin{array}{l}55 \\
65^{* *}\end{array}$ & $\begin{array}{l}23^{* * *} \\
37^{* * *}\end{array}$ \\
\hline \multicolumn{10}{|c|}{ JAK1/JAK2/TYK2-dependent cytokines } \\
\hline IL-6/pSTAT3 & 29 & $\begin{array}{l}22 \\
33\end{array}$ & $\begin{array}{l}39^{*} \\
54^{* * *}\end{array}$ & NS & & & 32 & $\begin{array}{l}27 \\
39\end{array}$ & $\begin{array}{l}46^{* * * *} \\
61^{* * *}\end{array}$ \\
\hline IL-10/pSTAT3 & 27 & $\begin{array}{l}21 \\
29\end{array}$ & $\begin{array}{l}39^{*} \\
53^{* * *}\end{array}$ & 23 & $\begin{array}{l}14^{*} \\
21\end{array}$ & $\begin{array}{l}34^{* *} \\
48^{* * *}\end{array}$ & 14 & $\begin{array}{l}17 \\
26^{*}\end{array}$ & $\begin{array}{l}25^{* * *} \\
40^{* * *}\end{array}$ \\
\hline IFN- $-/$ pSTAT1 & NS & & & NS & & & 37 & $\begin{array}{l}34 \\
46^{*}\end{array}$ & $\begin{array}{l}43^{* *} \\
61^{* * *}\end{array}$ \\
\hline IFN-a/pSTAT1 & 29 & $\begin{array}{l}32 \\
43^{*}\end{array}$ & $\begin{array}{l}24^{* *} \\
36^{* *}\end{array}$ & 25 & $\begin{array}{l}21 \\
31\end{array}$ & $\begin{array}{l}23 \\
37^{* * *}\end{array}$ & 21 & $\begin{array}{l}28 \\
40^{* * *}\end{array}$ & $\begin{array}{l}21 \\
32^{* * *}\end{array}$ \\
\hline IFN-a/pSTAT3 & 45 & $\begin{array}{l}48 \\
61\end{array}$ & $\begin{array}{l}40 \\
55^{*}\end{array}$ & NS & & & 62 & $\begin{array}{l}72 \\
81^{*}\end{array}$ & $\begin{array}{l}60 \\
76^{*}\end{array}$ \\
\hline IFN-a/pSTAT5 & 50 & $\begin{array}{l}52 \\
64\end{array}$ & $\begin{array}{l}49 \\
64^{* *}\end{array}$ & NS & & & 67 & $\begin{array}{l}75 \\
83^{*}\end{array}$ & $\begin{array}{l}62^{*} \\
78^{* *}\end{array}$ \\
\hline
\end{tabular}

Reported average daily percent STAT inhibition values are least squares estimates of mixed models as described in the "Statistical analysis" section. Protein binding was accounted for in the calculations. JAKis were administered once daily (baricitinib and upadacitinib) or twice daily (tofacitinib) ${ }^{*} p<0.01,{ }^{* *} p<0.001,{ }^{* * *} p<0.0001$ compared to baricitinib $4 \mathrm{mg}$

Bari baricitinib, G-CSF granulocyte colony-stimulating factor, GM-CSF granulocyte-macrophage colony-stimulating factor, IFN interferon, IL interleukin, JAK Janus kinase, JAKi JAK inhibitor, NK natural killer, NS no stimulation, PSTAT phosphorylated STAT, STAT signal transducer and activator of transcription, Tofa tofacitinib, TYK tyrosine kinase, Upa upadacitinib

monocytes was $55 \%$ and $65 \%$ for upadacitinib 15 - and 30 -mg doses, $32 \%$ and $45 \%$ for baricitinib 2- and 4-mg doses, and $23 \%$ and $37 \%$ for tofacitinib 5- and 10-mg doses, respectively (Table 3 and Additional file 1: Table S6, and Fig. 1c). A similar trend was observed for IL-3induced B cells. Percent STAT inhibition for G-CSF/ pSTAT3 (JAK2/TYK2) in monocytes was highest for tofacitinib and less for upadacitinib and baricitinib (Table 3 and Additional file 1: Table S6).

For cells stimulated by IL-6 (JAK1/2) and IL-10 (JAK1/TYK2), percent STAT inhibition was generally highest for tofacitinib and less for upadacitinib and baricitinib (Table 3 and Additional file 1: Table S5-S7, and Fig. 1d). For IL-6/pSTAT3 in CD4+ T cells, percent STAT inhibition was $39 \%$ and $54 \%$ for tofacitinib 5- and 10-mg doses, $22 \%$ and $33 \%$ for upadacitinib 15 and $30-\mathrm{mg}$ doses, and $17 \%$ and $29 \%$ for baricitinib 2 and 4-mg doses, respectively (Table 3 and Additional file 1: Table S6, and Fig. 1d). A similar trend was observed in IFN- $\gamma$ - (JAK1/2) induced cell types (Table 3 and Additional file 1: Tables S5-S7, and Fig. 1e). The percent STAT inhibition for IFN- $\alpha$ - (JAK1/TK2) induced PSTAT1, 3 , and 5 was generally highest for upadacitinib and tofacitinib and less for baricitinib, across cell types (Table 3 and Additional file 1: Table S5).

\section{Discussion}

The introduction of multiple JAKis into clinical practice, each with distinct selectivity across the JAK family members as determined by in vitro kinase assays, poses 
obvious questions as to the relative functional impact of such differences. Herein, we characterized the in vitro cellular pharmacology of baricitinib, upadacitinib, and tofacitinib, coupled to their in vivo PK, to determine their effects (at human oral doses that are approved or included in late phase clinical studies) on distinct cytokine pathways involved in the pathogenesis of RA.

Tofacitinib and upadacitinib, for example, were the most potent inhibitors of the JAK1/3-dependent cytokines tested. Moreover, lower $\mathrm{IC}_{50}$ values and increased time above $\mathrm{IC}_{50}$ for tofacitinib and upadacitinib, compared for example with baricitinib, translated to a greater overall inhibition of STAT signaling during the 24-h dosing interval for JAK1/3-dependent cytokines. Inhibition of this particular pathway may have potential impact on lymphocyte activation. Notably, IL-15 and IL-21 induce the maturation and function of NK cells and this may be of relevance to the changes in peripheral blood NK cell numbers reported in JAKi trials in RA [9, 15-19]. Relationships between the durability of STAT inhibition by any given JAKi and overall changes in lymphocyte subpopulations observed in RA clinical trials with these molecules remains to be determined.

Upadacitinib, baricitinib, and tofacitinib inhibited the JAK2/2 or JAK2/TYK2 signaling cytokines IL-3, GMCSF, and G-CSF, albeit to varying degrees. Upadacitinib proved the most potent inhibitor of IL-3 and GM-CSF (JAK2/2), followed by baricitinib and tofacitinib, while tofacitinib proved the most potent inhibitor of G-CSF (JAK2/TYK2), followed by upadacitinib and baricitinib. Both G-CSF and GM-CSF may contribute to RA pathogenesis through the activation, differentiation, and survival of myeloid cells [20]. Indeed, blockade of GM-CSF receptor with the humanized monoclonal antibody mavrilimumab was effective in a phase 2 clinical trial in RA [21]. Baricitinib and other JAKis with activity against JAK2 may attenuate RA pathogenesis in part through inhibiting GM-CSF-mediated cellular responses.

With respect to JAK1/2-dependent cytokine signaling, baricitinib, upadacitinib, and tofacitinib were all inhibitors of IL- 6 and IFN- $\gamma$ (JAK1/2), and IL-10 and IFN- $\alpha$ (JAK1/ TYK2) signaling, although differences in potency emerged. Tofacitinib proved the most potent inhibitor of IL-6, IFN- $\gamma$, and IL-10 signaling, followed by upadacitinib and baricitinib, while upadacitinib and tofacitinib were the most potent inhibitors of IFN- $\alpha$ signaling. Interleukin- 6 is a pleiotropic pro-inflammatory cytokine that contributes to synovial inflammation, articular joint destruction, and some of the systemic features observed in RA [22]. Baricitinib and other JAKis may be effective in the treatment of RA in part by IL-6 inhibition, which has been validated as a therapeutic target in RA patients by the monoclonal antibody tocilizumab [23]. Interleukin-10, IFN- $\alpha$, and IFN- $\gamma$ are also likely contributors to RA pathogenesis, and inhibition of these responses may contribute to the mechanism of JAKis in RA treatment; lesser inhibition of IL-10 may be desirable as the net effects of this cytokine have been described as anti-inflammatory in RA [4, 24].

Upadacitinib has been reported to be a selective JAK1 inhibitor [8, 9]. Data in this study, however, showed that at clinically relevant doses, upadacitinib was the most potent inhibitor among the drugs tested of the JAK2dependent cytokines IL-3 and GM-CSF. These findings indicate that upadacitinib would also inhibit cytokines other than those primarily dependent upon JAK1 at clinically effective concentrations. Data in this study also demonstrate that tofacitinib has moderate activity against JAK2 and TYK2, in addition to activity against JAK1 and JAK3. Together, these findings suggest that conclusions about potency and selectivity drawn from refined in vitro kinase assays may differ when considering the more biologically relevant concept of signal blockade at the cellular level in the context of circulating drug concentrations at doses used in humans.

There are limitations to the conclusions that can be drawn from this analysis. One potential limitation with this study is that high concentrations of cytokine can right shift the $\mathrm{IC}_{50}$ values if the STAT substrate is limiting. This could potentially be limiting our interpretation of the data for upadacitinib. However, we investigated this phenomenon and adjusted the cytokine concentrations where necessary, but some cytokines were either insensitive to concentration or could not be lowered without compromising the data in an alternate cell type or STAT readout. It would have been valuable to assess the ability of each JAKi to impair the half maximal response concentration $\left(\mathrm{EC}_{50}\right)$ of these cytokines, but would require extensive tuning of each cytokine in each cell type, which is well beyond the scope of this initial report. Another limitation was that the statistical analysis of this study used a single, average PK profile and did not reflect inter-subject variability. Furthermore, all $\mathrm{IC}_{50}$ values were calculated from PBMCs derived from healthy volunteers and extrapolated where available to RA patient exposure curves. Finally, while this study describes a reproducible cellular test system in which to test the molecules, the drugs were introduced to unstimulated healthy volunteer cells, which were then stimulated. Looking at how such molecules perform in previously activated cells may be more relevant to in vivo inflammatory disease conditions. This may warrant future study, for instance using samples from patients with active inflammatory disease.

\section{Conclusions}

These data demonstrate that JAKis display different in vitro pharmacologic profiles which, when coupled with their in vivo PK profiles, suggest that they may work via 
modulating differing cytokine pathways to varying degrees and durations over a 24-h dosing interval. None of the JAKis studied completely or continuously inhibited an individual cytokine signaling pathway over the dosing interval when assessed by STAT inhibition or time over $\mathrm{IC}_{50}$, respectively. These observations may have implications for the efficacy and safety profiles observed with different JAKis across different disease states. This in turn may inform JAKi development tailored to capitalize on the most clinically beneficial pharmacological features that will emerge as several agents are established in clinical practice.

\section{Additional file}

Additional file 1: Table S1. $I_{50}$ values in $B$ cells and $C D 8+T$ cells. Table S2. Hours per day above $I_{50}$ in $B$ cells and CD8+ T cells: baricitinib 4-mg. Table S3. Hours per day above IC ${ }_{50}$ in CD4+ T cells, NK cells, and monocytes: baricitinib 2-mg. Table S4. Hours per day above $\mathrm{IC}_{50}$ in B cells and CD8+ T cells: baricitinib 2-mg. Table S5. Average daily percent STAT inhibition in B cells and CD8+ T cells: baricitinib 4-mg. Table S6. Average daily percent STAT inhibition in CD4+ T cells, NK cells, and monocytes: baricitinib 2-mg. Table S7. Average daily percent STAT inhibition in B cells and CD8+ T cells: baricitinib 2-mg. Figure S1. Select representative histogram plots for cytokine-induced STAT phosphorylation (DOCX 278 kb)

\section{Abbreviations}

CRC: Concentration-response curve; $\mathrm{EC}^{50}$ : Half maximal response concentration; CRC: Concentration-response curve; G-CSF: Granulocyte colony-stimulating factor; GM-CSF: Granulocyte-macrophage colonystimulating factor; $\mathrm{IC}_{50}$ : Half maximum inhibitory concentration; IFN: Interferon; LL: Interleukin; JAK: Janus kinase; JAKi: JAK inhibitor; MFI: Mean fluorescence intensity; NK: Natural killer; PBMC: Peripheral blood mononuclear cell; PK: Pharmacokinetic; PSTAT: Phosphorylated STAT; QD: Once daily; RA: Rheumatoid arthritis; SE: Standard error; STAT: Signal transducer and activator of transcription; TYK: Tyrosine kinase

\section{Acknowledgements}

The authors would like to acknowledge Julie Sherman (Eli Lilly) for figure assistance. PCT would like to acknowledge support by the National Institute for Health Research (NIHR) Oxford Biomedical Research Centre (BRC) and by AR UK. This manuscript is based on work presented at the 2017 ACR/ARHP Annual Meeting: McInnes IB et al. Arthritis Rheumatol. 2017;69 (suppl 10) [abstract].

\section{Authors' contributions}

All authors participated in the analyses and interpretation of data, wrote or critically reviewed the manuscript, and reviewed and approved the final version.

\section{Authors' information}

Jonathan Lee: Contributions to this article while an employee of Eli Lilly; the current affiliation is PDD4Patients LLC, Indianapolis, IN, USA.

\section{Funding}

This study and manuscript were sponsored by Eli Lilly and Company, under license from Incyte Corporation.

\section{Availability of data and materials}

Eli Lilly and Company provides access to relevant anonymized patient-level data from studies on approved medicines and indications as defined by the sponsor-specific information on www.clinicalstudydatarequest.com. For details on submitting a request, see the instructions provided at www.clinicalstudydatarequest.com.

\section{Ethics approval and consent to participate}

Whole blood samples from healthy volunteers were obtained under a protocol approved by the Institutional Review Board of Stanford University (reference numbers 5136 and 6208). The IRB provided a Waiver of Consent because leukocyte-enriched fractions are by-products of the blood donation.

\section{Consent for publication}

Not applicable.

\section{Competing interests}

IBM has received grants and personal fees from AbbVie, Eli Lilly and Company, Janssen, Novartis, Pfizer, and Roche. NLB, REH, WLM, SN, RAO, GR, TPR, XZ, and SHZ are employees and shareholders of Eli Lilly and Company. $J \mathrm{~L}$ was an employee and shareholder of Eli Lilly and Company when contributions to this article were made. He is now an employee of PDD4Patients LLC. TW is an employee and shareholder of Primity Bio. PCT has received grants and personal fees from Eli Lilly and Company, Galapagos, and UCB. He has received grants from Abide Therapeutics and Celgene and personal fees from AbbVie, Biogen, GSK, Janssen, Novartis, Pfizer, and Sandoz.

\section{Author details}

${ }^{1}$ Institute of Infection, Immunity and Inflammation, University of Glasgow, University Avenue, Glasgow G128QQ, UK. ${ }^{2}$ Eli Lilly and Company, Indianapolis, IN, USA. ${ }^{3}$ Primity Bio, Fremont, CA, USA. ${ }^{4}$ Botnar Research Centre, Nuffield Department of Orthopaedics, Rheumatology and Musculoskeletal Sciences, University of Oxford, Oxford, UK.

Received: 17 December 2018 Accepted: 22 July 2019

Published online: 02 August 2019

\section{References}

1. Leonard WJ, O'Shea JJ. Jaks and STATs: biological implications. Annu Rev Immunol. 1998;16:293-322.

2. Smolen JS, Landewe R, Bijlsma J, et al. EULAR recommendations for the management of rheumatoid arthritis with synthetic and biological disease-modifying antirheumatic drugs: 2016 update. Ann Rheum Dis. 2017:76(6):960-77.

3. Tanaka Y. Current concepts in the management of rheumatoid arthritis. Korean J Intern Med. 2016;31(2):210-8.

4. Schwartz DM, Bonelli M, Gadina M, et al. Type I/II cytokines, JAKs, and new strategies for treating autoimmune diseases. Nat Rev Rheumatol. 2016;12(1):25-36.

5. Mclnnes IB, Buckley CD, Isaacs JD. Cytokines in rheumatoid arthritis shaping the immunological landscape. Nat Rev Rheumatol. 2016;12(1):63-8.

6. Fridman JS, Scherle PA, Collins R, et al. Selective inhibition of JAK1 and JAK2 is efficacious in rodent models of arthritis: preclinical characterization of INCB028050. J Immunol. 2010;184(9):5298-307.

7. Clark JD, Flanagan ME, Telliez JB. Discovery and development of Janus kinase (JAK) inhibitors for inflammatory diseases. J Med Chem. 2014;57(12):5023-38.

8. Voss J, Graff C, Schwartz A, et al. Pharmacodynamics of a novel Jak 1 selective inhibitor in rat arthritis and anemia models and in healthy human subjects [abstract]. Arthritis Rheum. 2013;65(supp 10). https://acrabstracts. org/abstract/pharmacodynamics-of-a-novel-jak1-selective-inhibitor-in-ratarthritis-and-anemia-models-and-in-healthy-human-subjects/. Accessed 30 July 2019

9. Genovese MC, Smolen JS, Weinblatt ME, et al. Efficacy and safety of ABT-494, a selective JAK-1 inhibitor, in a phase llb study in patients with rheumatoid arthritis and an inadequate response to methotrexate. Arthritis Rheumatol. 2016;68(12):2857-66.

10. Krutzik PO, Nolan GP. Fluorescent cell barcoding in flow cytometry allows high-throughput drug screening and signaling profiling. Nat Methods. 2006; 3(5):361-8.

11. Zhang X, Chua L, Ernest C, et al. Dose/exposure-response modeling to support dosing recommendation for phase III development of baricitinib in patients with rheumatoid arthritis. CPT Pharmacometrics Syst Pharmacol. 2017;6:804-13.

12. Mohamed ME, Zeng J, Song $\mathrm{IH}$, et al. Pharmacokinetics of ABT-494 with the once-daily extended-release tablet formulation being utilized in the ongoing rheumatoid arthritis phase 3 trials [abstract]. Arthritis Rheumatol. 2016;68(suppl 10). https://acrabstracts.org/abstract/pharmacokinetics-of- 
abt-494-with-the-once-daily-extended-release-tablet-formulation-beingutilized-in-the-ongoing-rheumatoid-arthritis-phase-3-trials/. Accessed 30 July 2019.

13. Klunder B, Mohamed MF, Othman AA. Population pharmacokinetics of upadacitinib in healthy subjects and subjects with rheumatoid arthritis: analyses of phase I and II clinical trials. Clin Pharmacokinet. 2018;57(8):977-88.

14. Clinical pharmacology and biopharmaceutics review_NDA203214. Secondary clinical pharmacology and biopharmaceutics review_ NDA203214. 2012. https://www.accessdata.fda.gov/drugsatfda_docs/nda/2 012/203214Orig1s000ClinPharmR.pdf. Accessed 22 Aug 2017.

15. Steel JC, Waldmann TA, Morris JC. Interleukin-15 biology and its therapeutic implications in cancer. Trends Pharmacol Sci. 2012;33(1):35-41.

16. Tangye SG. Advances in IL-21 biology - enhancing our understanding of human disease. Curr Opin Immunol. 2015;34:107-15.

17. Hodge JA, Kawabata TT, Krishnaswami S, et al. The mechanism of action of tofacitinib - an oral Janus kinase inhibitor for the treatment of rheumatoid arthritis. Clin Exp Rheumatol. 2016;34(2):318-28.

18. Kremer JM, Emery P, Camp HS, et al. A phase Illb study of ABT-494, a selective JAK-1 inhibitor, in patients with rheumatoid arthritis and an inadequate response to anti-tumor necrosis factor therapy. Arthritis Rheumatol. 2016;68(12):2867-77.

19. Tanaka Y, Mclnnes IB, Taylor PC, et al. Characterization and changes of lymphocyte subsets in baricitinib-treated patients with rheumatoid arthritis: an integrated analysis. Arthritis Rheumatol. 2018;70(12):1923-32.

20. Wicks IP, Roberts AW. Targeting GM-CSF in inflammatory diseases. Nat Rev Rheumatol. 2016;12(1):37-48.

21. Burmester GR, Weinblatt ME, McInnes IB, et al. Efficacy and safety of mavrilimumab in subjects with rheumatoid arthritis. Ann Rheum Dis. 2013; 72(9): 1445-52.

22. McInnes IB, Schett $G$. The pathogenesis of rheumatoid arthritis. N Engl J Med. 2011;365(23):2205-19.

23. Smolen JS, Beaulieu A, Rubbert-Roth A, et al. Effect of interleukin-6 receptor inhibition with tocilizumab in patients with rheumatoid arthritis (OPTION study): a double-blind, placebo-controlled, randomised trial. Lancet. 2008; 371(9617):987-97.

24. Castillo P, Kolls JK. IL-10: a paradigm for counterregulatory cytokines. J Immunol. 2016;197(5):1529-30.

\section{Publisher's Note}

Springer Nature remains neutral with regard to jurisdictional claims in published maps and institutional affiliations.

Ready to submit your research? Choose BMC and benefit from:

- fast, convenient online submission

- thorough peer review by experienced researchers in your field

- rapid publication on acceptance

- support for research data, including large and complex data types

- gold Open Access which fosters wider collaboration and increased citations

- maximum visibility for your research: over $100 \mathrm{M}$ website views per year

At $\mathrm{BMC}$, research is always in progress.

Learn more biomedcentral.com/submissions 